\title{
FORMAÇÃO DE PROFESSORES: RELATO DE EXPERIÊNCIAS NO CONTEXTO DO PIBID/ UESB
}

\author{
Fabiana Andrade Santos* \\ Virginia Silveira Baldow ${ }^{* *}$
}

RESUMO: Este artigo procura refletir o ser professor e as suas implicações, mediante a triangulação do pensar-fazer-pensar as aulas de Língua Portuguesa. Para isso, será socializada uma experiência (ação) oriunda do projeto intitulado Grandes Histórias Escritas por Todos Nós, desenvolvido no Colégio Estadual Fernando Spínola, durante o ano letivo de 2019. Cumpre esclarecer que o referido projeto é um desdobramento do Subprojeto de Língua Portuguesa/ Fundamental II do Programa de Institucional de Bolsas de Iniciação à Docência - Pibid/2018. Protagonizaram a elaboração e o desenvolvimento dessa experiência (ação) os seguintes sujeitos: as coordenadoras do referido subprojeto; a professora supervisora do ensino fundamental do Colégio Estadual Fernando Spínola; 07 licenciandos do Curso de Letras Vernáculas da Uesb, Campus Vitória da Conquista, agora, ex-bolsistas de iniciação à Docência do Pibid e, também, os alunos dos $7^{\circ}$ e $9^{\circ}$ anos do Ensino Fundamental do referido colégio, em Vitória da Conquista. Como resultado desse processo de (trans) formação docente/discente houve a publicação da Revista Pequenos Grandes Escritores a qual revela que a formação docente, fomentada por meio de políticas públicas, deve ser experienciada não apenas pelos eixos de preparação acadêmica; preparação profissional e prática profissional, mas igualmente, mediante uma formação que não prescinde das vivências e do envolvimento pessoal de todos os envolvidos.

PALAVRAS-CHAVE: Formação de professor; Pibid; Vivências.

\section{Introdução}

Este trabalho apresenta o desdobramento de uma monitoria didática integrada ao Subprojeto Língua Portuguesa/Ensino Fundamental II do Programa de Bolsa de Iniciação à Docência-PIBID/UESB/2018. A monitoria foi desenvolvida em classes de $7^{\circ}$ e $9^{\circ}$ anos do Ensino Fundamental II, durante o ano letivo de 2019, na cidade de Vitória da Conquista. O projeto realizado intitulou-se Grandes Histórias Escritas por Todos Nós e teve como participantes os seguintes sujeitos: coordenadoras do subprojeto, a supervisora, representante do

\footnotetext{
${ }^{*}$ Mestre em Letras e Linguística pela Universidade Federal da Bahia (Ufba). Professora Assistente da Universidade Estadual do Sudoeste da Bahia (Uesb).

** Mestre em Literatura e Diversidade Cultural pela Universidade Estadual de Feira de Santana (Uefs). Professora da Universidade Estadual do Sudoeste da Bahia (Uesb).
} 
Colégio Fernando Spínola, 7 bolsistas de Iniciação à docência e os alunos das turmas de $7^{\circ}$ e $9^{\circ}$ anos da referida escola. O referido projeto se desenvolveu ao longo das três unidades letivas envolvendo, além da disciplina Língua portuguesa, a disciplina "Artes" que colaborou com as ilustrações dos textos produzidos.

As aulas foram planejadas segundo as seguintes orientações metodológicas: a) $1^{\text {a }}$ etapa - Leituras e interpretações dos gêneros: poemas, fábulas, contos, crônicas; produções textuais com escrita e reescrita; b) $2^{\text {a }}$ etapa - Leituras e interpretações de acrósticos, haicais, trovas e cordéis; produções textuais com escrita e reescrita; c) $3^{a}$ etapa - produção de obras artísticas para as ilustrações dos textos produzidos. d) $4^{\text {a }}$ etapa - culminância: organização de um livro e uma revista com os textos produzidos pelos alunos. Aqui, apresentaremos os resultados obtidos por meio da revista produzida e dividimos a nossa reflexão em três seções. Na primeira, apresentamos uma reflexão normativista da Formação Docente pautadas nas prescrições expostas em três artigos da LDB/96, a saber, 61, 62 e 67. Em seguida, na seção intitulada "O Ser Professor no contexto do PIBID/Subprojeto Língua Portuguesa" debatemos a formação docente alicerçada, também, nas vivências dos protagonistas que participaram de todo o projeto já contextualizado nas linhas iniciais desta introdução. Finalmente, na última seção apresentamos o "Ser Professor e sua Formação" utilizando, para isso, os depoimentos dos licenciando que participaram do projeto.

\section{A LDB e a formação docente}

Compreendemos que pensar a formação docente impõe-nos analisar as diretrizes emanadas das suas normatizações pois é, também, por meio delas que muitos vozeamentos surgem, sejam para alicerçá-las, sejam para confrontá-las, sejam para reforçá-las.

No nosso contexto, apoiamo-nos na Lei de Diretrizes e Bases da Educação Nacional, especificamente, no Título VI denominado "Dos Profissionais da Educação" com realce a alguns artigos, quais sejam, 61, 62 e 67.

Art. 61. Consideram-se profissionais da educação escolar básica os que, nela estando em efetivo exercício e tendo sido formados em cursos reconhecidos, são: 
III - trabalhadores em educação, portadores de diploma de curso técnico ou superior em área pedagógica ou afim.. (Incluído pela Lei no 12.014 , de 2009)

Parágrafo único. A formação dos profissionais da educação, de modo a atender às especificidades do exercício de suas atividades, bem como aos objetivos das diferentes etapas e modalidades da educação básica, terá como fundamentos: (Incluído pela Lei n 12.014 , de 2009)

II - a associação entre teorias e práticas, mediante estágios supervisionados e capacitação em serviço; (Incluído pela Lei $\mathrm{n}^{\mathrm{o}}$ 12.014, de 2009)

III - o aproveitamento da formação e experiências anteriores, em instituições de ensino e em outras atividades. (Incluído pela Lei no 12.014, de 2009)

Art. 62. A formação de docentes para atuar na educação básica farse-á em nível superior, em curso de licenciatura plena, admitida, como formação mínima para o exercício do magistério na educação infantil e nos cinco primeiros anos do ensino fundamental, a oferecida em nível médio, na modalidade normal. (Redação dada pela lei $\mathrm{n}^{\circ} 13.415$, de 2017)

$[\ldots]$

Art. 62-A. A formação dos profissionais a que se refere o inciso III do art. 61 far-se-á por meio de cursos de conteúdo técnico-pedagógico, em nível médio ou superior, incluindo habilitações tecnológicas. (Incluído pela Lei nº 12.796, de 2013)

Parágrafo único. Garantir-se-á formação continuada para os profissionais a que se refere o caput, no local de trabalho ou em instituições de educação básica e superior, incluindo cursos de educação profissional, cursos superiores de graduação plena ou tecnológicos e de pós-graduação. (Incluído pela Lei ${ }^{\circ}$ 12.796, de 2013)

Art. 67. Os sistemas de ensino promoverão a valorização dos profissionais da educação, assegurando-lhes, inclusive nos termos dos estatutos e dos planos de carreira do magistério público:

I - ingresso exclusivamente por concurso público de provas e títulos; II - aperfeiçoamento profissional continuado, inclusive com licenciamento periódico remunerado para esse fim;

III - piso salarial profissional;

IV - progressão funcional baseada na titulação ou habilitação, e na avaliação do desempenho;

V - período reservado a estudos, planejamento e avaliação, incluído na carga de trabalho;

VI - condições adequadas de trabalho.

$\int 1^{\circ} \mathrm{A}$ experiência docente é pré-requisito para o exercício profissional de quaisquer outras funções de magistério, nos termos das 
normas de cada sistema de ensino. (Renumerado pela Lei $\mathrm{n}^{\circ} 11.301$, de 2006)

Fazendo uma análise desses dispositivos, depreende-se que o legislador teve como preocupação definir quem são considerados os profissionais da educação escolar básica e as habilitações necessárias para o seu exercício, priorizando, assim, um viés engessado, consubstanciado na sua especialidade. No que se refere à formação, verifica-se a presença de algumas expressões - aperfeiçoamento, capacitação e treinamento - que nos levam a presumir sua visão apartada do contexto da escola, da vivência docente e da sua pessoa enquanto sujeito.

Compreendemos ainda que nesses artigos há uma consonância com uma perspectiva mecanicista e adaptativa da formação docente objetivando levar o professor a seguir diretrizes. Além disso, é verificável uma concepção gerencial muita afinada com uma perspectiva produtivista cujo corolário devem ser resultados impostos por organismos e instituições que não vivenciam o "chão" da escola.

Outrossim, o caráter assistencialista que é dispensado à formação profissional e a necessidade de capacitar o professor para o exercício da docência e para continuar no seu exercício são perspectivas balizadoras desses artigos. Nessa toada, o professor antagonizaria a sua formação e as suas necessidades, cabendo ao Estado decidir o quê, para quê e quando promover condições para o seu aperfeiçoamento.

Achamos oportuno, ainda, acrescer que expressões como aperfeiçoamento, capacitação e treinamento desvelam concepções e metas próprias de agentes antiéticos. O vocábulo aperfeiçoamento, por exemplo, pressupõe a ideia de que há um hiato, um déficit, na formação do professor que precisa ser preenchido por meio de capacitação e treinamento. Essas últimas expressões, também inapropriadas, demonstram uma concepção muito afinada com uma visão utilitarista do professor.

Trazemos essa reflexão porque entendemos que o ser ético e o agir ético devem estar alicerçados no pensar-fazer-pensar o outro. (Trans)formar para a ética implica um (re)definir diário em que o conhecimento, para além de estar pautado em cientificidade e metodologias, deve se comprometer com o outro. Sendo assim, 
O foco da mudança relaciona-se com a aceitação de que a formação é um processo subjetivo, ou seja, o professor se forma como uma condição de sua mobilização para tal. (NOVOA, 1994) Os estímulos externos podem ser importantes, mas precisam contar com o significado que o professor atribui à experiência de formação. Reconhece-se que essa experiência inclui as trajetórias de vida, os referentes culturais e os valores sociais em um amálgama de possibilidades de construção da profissionalidade docente, sendo entendida como a profissão em ação. (CUNHA, 2013, p. 619)

\section{O ser professor no contexto do PIBID/subprojeto Língua Portuguesa}

Compreendemos que o Programa Institucional de Bolsas de Iniciação à Docência/Pibid é um projeto político que, além de incentivar a formação continuada de professores da educação básica, pode proporcionar experiências catalisadoras de novos fazeres pedagógicos, por meio da inserção de estudantes de licenciaturas em escolas públicas, estabelecendo a iniciação destes no ofício docente. As ações aqui compartilhadas e refletidas são resultantes da interlocução realizada entre coordenadoras, supervisora e licenciandos a partir das propostas didáticas construídas em reuniões do Subprojeto Língua PortuguesaEnsino Fundamental II, cujos objetivos priorizados foram: a) incentivar a formação de docentes em nível superior para a educação básica; b) contribuir para a valorização do magistério; c) elevar a qualidade da formação inicial de professores nos cursos de licenciatura, promovendo a integração entre educação superior e educação básica; d) inserir os licenciandos no cotidiano de escolas da rede pública de educação;

\section{e e) mobilizar os professores da educação básica quanto à coformação dos licen-} ciandos.

Tais objetivos tinham como espinha dorsal possibilitar o protagonismo dos licenciandos em vivências e experiências (do)discentes. Este intento se assenta no princípio de que, na constituição do ser docente, é intrínseco o pensar-fazer-pensar, ou seja, refletir sempre: antes, durante e após qualquer ato pedagógico realizado em sala de aula. Assim, impôs-se a nós discutir as contribuições de NÒVOA (1995) sobre os valores da profissão docente que transcende o pensamento simplista e confortável de inovações metodológicas. Para NÒVOA (1995) mais do que um lugar de aquisição de técnicas e de conhecimentos, 
a formação de professores é o momento-chave da socialização e da configuração profissional" (NÒVOA, 1995, p. 26)

[...] a história da profissão docente é indissociável do lugar que seus membros ocupam nas relações de produção e do papel que eles jogam na manutenção da ordem social. Os docentes não vão somente responder uma necessidade social, mas também vão criá-la. A grande operação histórica da escolarização jamais teria sido possível sem a conjugação de vários fatores de ordem econômica e social, mas é preciso não esquecer que os agentes desse empreendimento foram os professores. (NÒVOA, 1995, p. 23)

Dessa forma, reconhecendo a diferença fundamental que o professor faz não somente na escola, mas também, nos âmbitos social, político e cultural, tínhamos o grande desafio de debater as implicações que se revelavam entre o pensar-fazer-pensar as aulas de língua portuguesa, alicerçado em uma prática problematizadora, comprometida com a libertação, posto que se funda na criatividade, estimulando assim "a reflexão e a ação verdadeiras dos homens sobre a realidade" (FREIRE 2019, p. 101). Para tanto, compreendemos que, nesse mister, não se prescinde do nosso reconhecimento de seres "inacabados, inconclusos em uma realidade que, sendo histórica, também é igualmente inacabada (FREIRE 2019, p. 101).

Não obstante esse reconhecer-se, sentimos a necessidade de debater com os colegas em formação a necessidade de uma prática-formativa que considerasse também as vivências dos alunos do Colégio Fernando Spínola. Sendo assim, ampliamos a nossa lente pensando a formação docente encapsulada por vivências e valores de todos os sujeitos envolvidos. Isso significa pautar, sempre, um planejamento-formativo comprometido com pessoas. Logo, no processo formativo que havíamos proposto, para além de construir um plano de atividades que contemplasse rodas de estudos de textos teóricos; oficinas; monitorias didáticas e o "garimpo textual como ação didático-pedagógica” (MODL; BIAVATI e SOUZA, 2016, p. 190), com mais vigor, desafiamo-nos a priorizar, juntamente com os bolsistas, propostas que contemplassem vivências e balanços retrospectivos que possibilitassem produzir a "sua" vida, o que no caso dos professores é também produzir a "sua" profissão. (NÒVOA, 1995, p. 28) 


\section{O pensar-fazer-pensar docente por meio do projeto “Grandes histórias escritas por}

\section{todos nós”}

Achamos oportuno inaugurar esta seção transcrevendo a reflexão de Holly \&

McLoughlin (1989, apud NÒVOA, 1995, p. 31), sobre a formação de professores:

Já começamos, mas estamos longe do fim. Começamos por realizar ações pontuais de formação continuada, mas evoluímos no sentido de as enquadrar num contexto mais vasto do desenvolvimento profissional e organizacional. Começamos por encarar os professores isolados e a título individual, mas evoluímos no sentido de os considerar integrados em redes de cooperação e de colaboração profissional. Passamos de uma formação por catálogo para uma reflexão na prática e sobre a prática. Modificamos a nossa perspectiva de um modelo de formação de nossos professores para programas diversificados e alternativos de formação contínua. Mudamos as nossas práticas de investigação sobre os professores para uma investigação com os professores e até para uma investigação pelos professores. Estamos evoluindo no sentido de uma profissão que desenvolve os seus próprios sistemas e saberes, através de percursos de renovação permanente que a definem como uma profissão reflexiva e científica. (Holly \& McLoughlin ,1989, apud NÒVOA, 1995, p. 31)

O nosso "começo" materializou-se com o projeto Grandes histórias escritas por todos nós, idealizado pelos bolsistas do PIBID, com posterior parceria firmada com os Centros Juvenis de Ciência e Cultura (CJCC) de Vitória da Conquista. O objetivo geral dessa proposta era desenvolver a competência comunicativa dos estudantes do Ensino Fundamental II. Para tanto, era necessário transcender "a concepção de escrita reduzida aos aspectos formais do sistema linguístico, ou seja, à gramática e à correção ortográfica, e a uma didática estrutural e reprodutivista que não se coaduna com uma didática para o pensamento crítico." (EMEDIATO, 2016, p. 144).

Isso posto, os bolsistas se sentiram desafiados a pensar-fazer-pensar a sua prática, mediante a elaboração de uma proposta pedagógica que confrontasse o sistema tradicional de ensino, cuja visão da escrita homogeneíza o texto num processo contínuo em que se desconsideram os significados e funções emergentes de todo enunciado, como por exemplo, a sua natureza dialógica, as suas condições de produção, assim como a interação com 
as vozes que compõem o texto escrito. A partir dessa reflexão crítica, os licenciandos, juntamente com a supervisora, foram instigados a desenvolver uma monitoria didática pautada em um planejamento que contemplasse o dinamismo da escrita considerando sempre as relações sociodiscursivas e dialógicas próprias da natureza de todo enunciado. A partir desse processo crítico- reflexivo, originou-se o projeto Grandes histórias escritas por todos nós o qual foi elaborado, considerando as vivências dos sujeitos envolvidos.

Cumpre-nos esclarecer que um dos "resultados" dessa proposta foi a publicação da revista Pequenos Grandes Escritores. Nela estão contidos gêneros textuais, produzidos pelos alunos dos $7^{\circ}$ e $9^{\circ}$ anos do CEFS, quais sejam: acrósticos, haicais, trovas, cordéis, poemas, contos e fábulas. A temática desses gêneros era livre cabendo, assim, aos discentes/estudantes expressarem aquilo que mais conheciam e com que mais se identificavam, por meio da sua escrita e de ilustrações também construídas por eles, conforme apresentado abaixo.

Imagem 1 - Capa da revista Pequenos Grandes Escritores

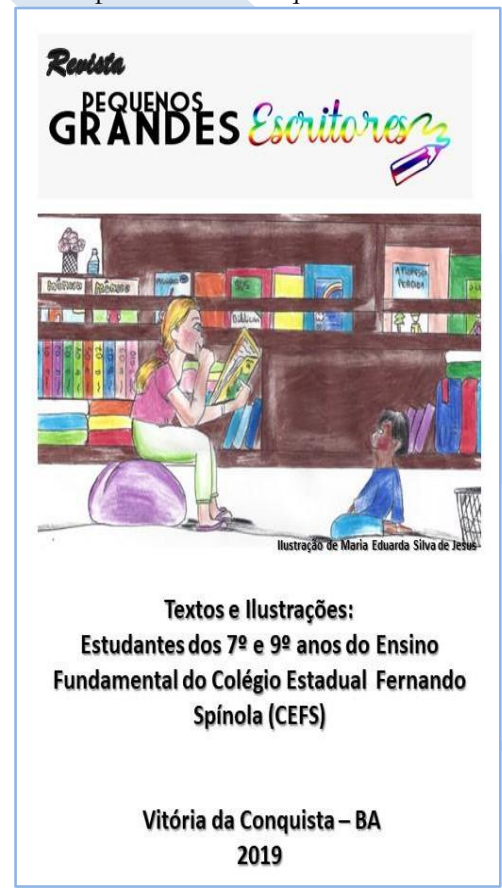

Fonte: Própria autoria (2019) 
Imagem 2 - Fundo da revista Pequenos Grandes Escritores

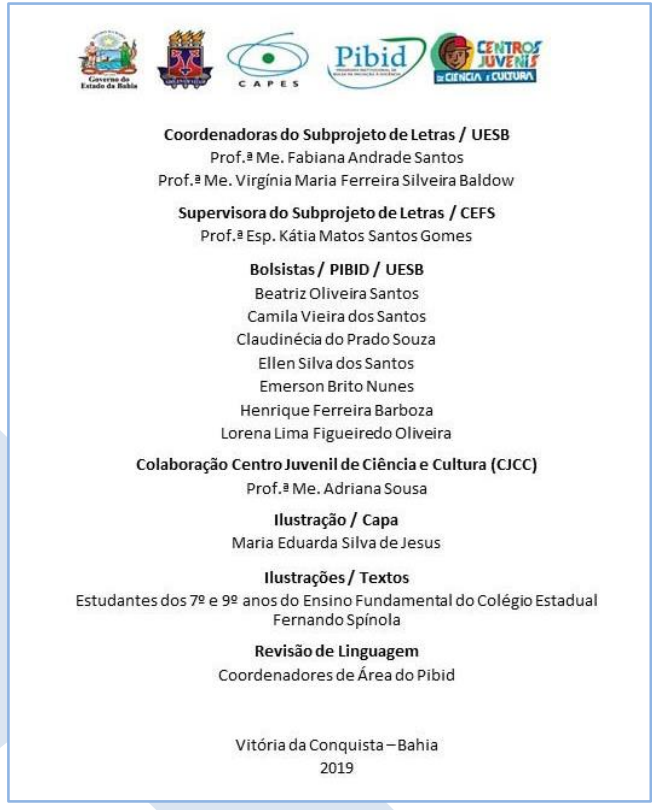

Fonte: Própria autoria (2019)

Imagem 3 - Acróstico Paz Mundial

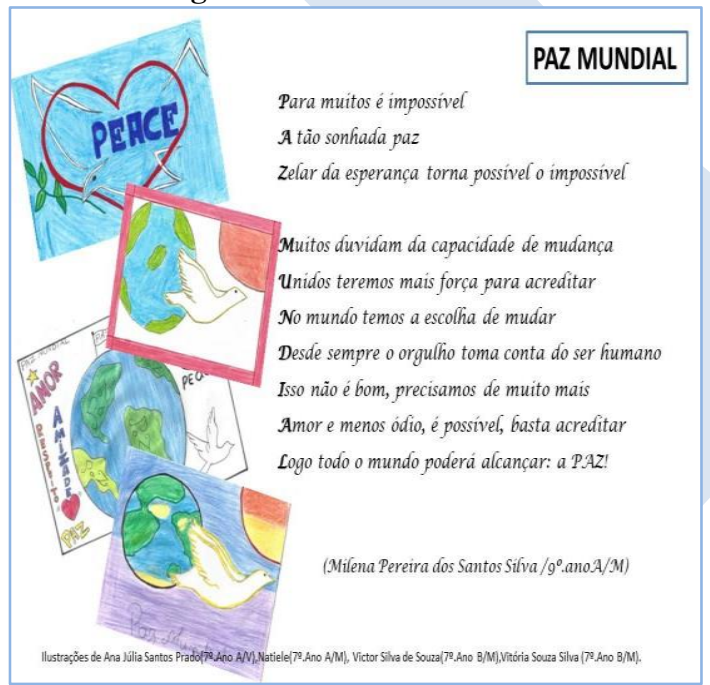

Fonte: Pequenos Grandes Escritores (2019) 
Imagem 4 - Acróstico Escola e Família

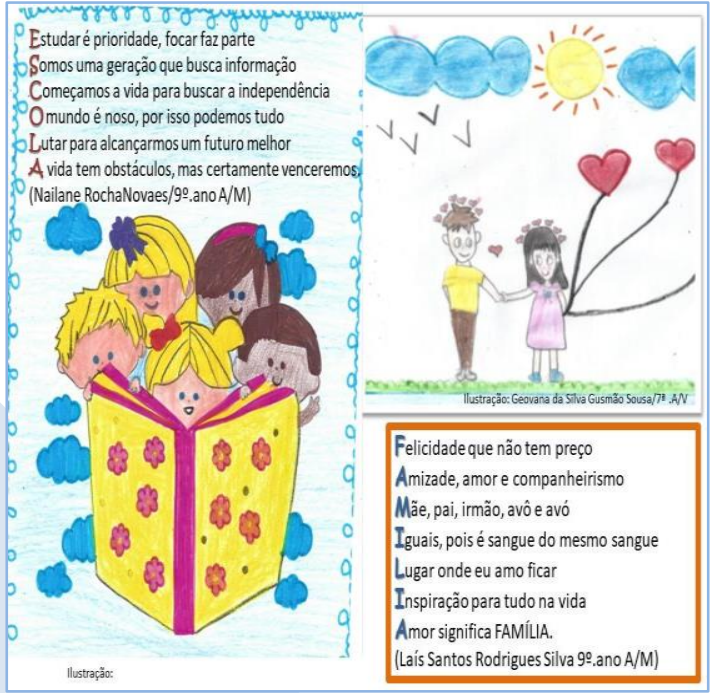

Fonte: revista Pequenos Grandes Escritores (2019)

\section{Imagem 5 - tipo}

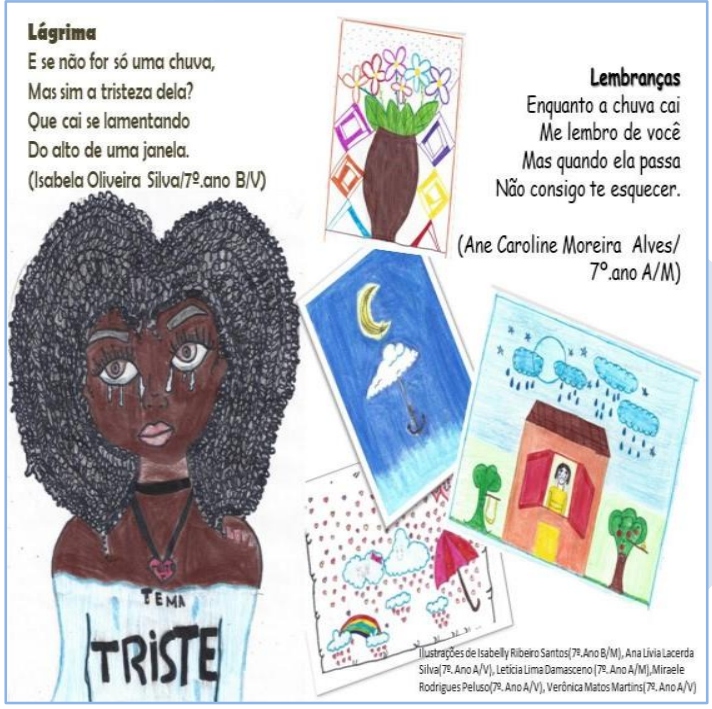

Fonte: Pequenos Grandes Escritores (2019) 


\section{Imagem 6 - tipo}

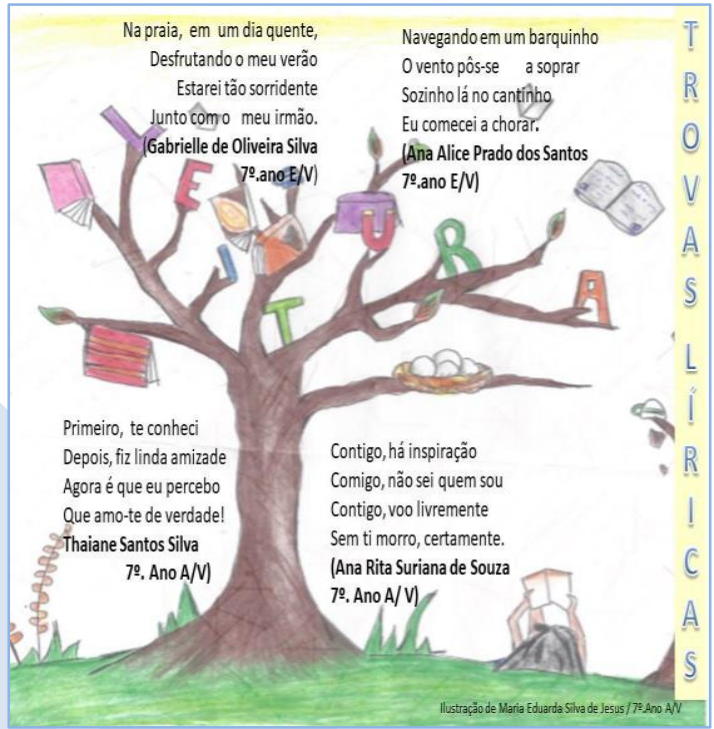

Fonte: Pequenos Grandes Escritores (2019)

Ao atentarmos para as produções dos alunos, observamos que as funções e significados atribuídos aos textos produzidos ultrapassaram o cumprimento estático de esquemas e regras automáticas, comumente exigidas em contextos tradicionais de ensino. É perceptível a manifestação de atitudes valorativas próprias das crenças e vivências dos alunos, desvelando livremente a subjetividade deles em seus textos. As amostras apresentadas atestam, portanto, a eficácia de uma prática pedagógica reflexiva e desafiadora que se pauta no fomento da leitura e escrita críticas, estimulando o aluno a captar e sugerir sentidos que vão muito além da superfície textual.

\section{Depoimentos dos bolsistas}

Os depoimentos colhidos de alguns bolsistas participantes do projeto respondem ao seguinte questionamento: Em que medida o PIBID contribuiu para você ser/fazer/tornar-se professor de Língua Portuguesa? 
1) Bem... não existem adjetivos suficientes para expressar o quão foi importante esses projetos do PIBID/UESB em parceria com o Colégio Fernando Spínola. Sem dúvidas, todos nós deixamos alguma sementinha de incentivo à leitura e escrita em toda aquela garotada. Além disso, foi muito única essa parceria porque aprendemos muito com os alunos. Deixamos estes à vontade em suas expressões no livro e na revista. Foram autônomos em todo esse processo, e isso que fez os projetos terem o sucesso que tiveram. Que tenhamos cada vez mais projetos voltados à escola e aos desejos artísticos dos estudantes.

Autorizo a divulgação deste depoimento Ádrian Henrique Ferreira Barboza

2) No início do ano letivo de 2019, a docente Kátia Matos propôs a nós, seus sete bolsistas do PIBID, a realização de oficinas de produção textual com as suas turmas do ensino fundamental. Nesta ocasião, nos disse que teríamos, também, um projeto surpresa; o que realmente foi uma surpresa, porque nem nos passava em mente que produziríamos um livro e uma revista. Tivemos bastante trabalho, pois precisaríamos todos conciliar o andamento das oficinas e a concretização dos projetos já mencionados. Graças a isso, conseguimos, juntamente aos estudantes do Colégio Estadual Fernando Espínola, trazer a público a revista Pequenos grandes escritores e o livro Grandes histórias escritas por todos nós, frutos, por sua vez, das produções dos alunos participantes das oficinas, bem como de textos dos alunos da mesma instituição produzidos para o concurso Lápis na Mão. Participar deste projeto foi uma das coisas que mais me deram fôlego para o exercício da profissão, foi um presente. Sinceramente, os resultados colhidos encheram de orgulho a todos os bolsistas e à docente, que trabalharam na revisão e organização dos textos dos alunos, os quais também vibraram ao ver seus textos presentes em um livro e em uma revista. Ora, um livro e uma revista! Maravilhoso foi ver nossos alunos como protagonistas!

Autorizo a divulgação deste depoimento Emerson Brito Nunes

3) Ao longo do período em que planejamos o projeto, muitas motivações nos influenciaram ao empreendimento desta jornada. Inicialmente, ao deliberarmos o projeto e transcrevê-lo ao papel, ainda com passos incipientes do planejamento, reconhecemos que haveria de exigir-nos a nós mesmos a perseverança, pois compreendíamos que muitos percalços seriam enfrentamos. Assim o foi, ao começar as atividades, vimos que o projeto só teria êxito se realizado coletivamente, buscamos, então, parcerias, aprimoramos o projeto, excluímos algumas atividades e, acima de tudo, sentamo-nos com os alunos, participamos da elaboração por meio do incentivo à criatividade deles mesmos, contemplamos o parto das ideias e, por fim, trabalhamos com a reescrita. Pois sabemos que uma obra de arte precisa, para chegar ao ponto final, passar por diversos processos de apuração. $\mathrm{Na}$ escrita esse processo não poderia ter sido feito senão pela reescrita. Desse modo, podemos chegar à conclusão de um projeto que esteve sempre como frente o protagonismo dos alunos e alunas do CEFS.

\section{Autorizo a divulgação deste depoimento} Claudinécia do Prado Souza

4) A experiência de participar do PIBID foi singular. Por mais que pensemos, sonhamos em como será estar em sala de aula, só conseguimos compreender estando nela. Participar do PIBID foi muito importante para minha formação docente e, muito mais que isso, possibilitou um convívio incrível e experiências necessárias do ensinar e aprender. O Projeto Oficina de Linguagem foi desafiador do início ao fim, pois, trabalhar leitura e escrita para alunos de ensino fundamental não 
é fácil. Com o desenvolvimento do livro "Grandes histórias escritas por todos nós" e da revista "Pequenos grandes escritores" percebo o quanto que valeu a pena esse projeto autoral. Sem dúvidas, o trabalho no Colégio estadual Fernando Spínola (CEFS) foi gratificante a medida em que gerou em mim a sensação de dever cumprido, como educadora que esteve presente não somente para estimular práticas de leitura e escrita, mas para incentivá-los aos valores da vida.

\section{Autorizo a divulgação deste depoimento}

Ellen Silia dos Santos

5) Ser bolsista do PIBID foi a realização de um sonho, visto que tivemos a oportunidade de interagir com os alunos e estar em uma escola, não mais como alunos, mas como docentes em processo de aprendizado. No ensejo, orientamos e produzimos a revista Pequenos Grandes Escritores e o livro Grandes Histórias Escritas por Todos Nós, ambos formados por produções literárias e artísticas dos alunos do Colégio Estadual Fernando Spínola. Para nós, o sentimento é de gratidão e a certeza de que vale a pena acreditar e investir na educação, pois se quisermos mudar o mundo, devemos começar valorizando o potencial da juventude, por meio de seus anseios e sonhos.

Autorizo a divulgação desse depoimento Beatriz Oliveira Santos

6) Participar do PIBID foi uma experiência única e gratificante. O contato com a escola, os alunos e professores me proporcionou vivenciar na prática o significado de ser professor. O PIBID oportunizou a troca de saberes, reflexões, o sentido do ser docente, entre outros momentos incríveis. Tenho muito orgulho de ter participado de dois lindos projetos desenvolvidos com alunos do Colégio Estadual Fernando Spínola (CEFS): a revista intitulada Pequenos Grandes Escritores e o livro Grandes Histórias Escritas por Todos Nós, produções de autoria dos próprios alunos. Observar o passo a passo na criação desses projetos, a criatividade, a delicadeza dos desenhos, as construções dos poemas, a alegria e satisfação estampados no rosto de cada aluno, sem dúvidas, foi muito emocionante.

Autorizo a divulgação desse depoimento Camila Vieira dos Santos

7) Eu, como aluna em formação, entendo a importância da leitura e escrita, pois elas promovem espaços do refletir, do produzir e reproduzir conhecimentos acerca do meio social dos alunos, tornando-os, assim, questionadores críticos, com opiniões seguras sobre vários aspectos que os rodeiam. Juntos, baseado nesse conhecimento, temos a oportunidade através do Programa (PIBID) a desenvolve-lo de forma livre, criativa e com muito cuidado. Tive em mente, a todo momento, uma compreensão de que o texto varia de um indivíduo para o outro, podendo suscitar várias produções. Aí se dá a extrema relevância em trabalhar com as leituras e mediações orais e produções em coletivo, onde o aluno pôde comparar seu olhar para o texto com outros olhares; pôde relacionar os contextos e, assim, compreender melhor o universo linguístico e semiótico que cada gênero. Além disso, vimos nos alunos entusiasmo um verdadeiro envolvimento com o que estavam fazendo, apresentando ideias para as publicações da revista e do livro e isso aumentava a cada encontro, e mesmo sabendo que o processo de correção era cansativo, me sentia realizada em prepará-los para algo grandioso. Nessa proposta de produção da revista e do livro não posso deixar de falar a importância da professora Kátia que nos orientou a todo momento, lado a lado, 
percebendo que os alunos ao protagonizar sua própria aprendizagem, se comporta como um sujeito reflexivo, dinâmico e crítico diante das realidades e representações sociais que foram necessárias devido à construção tanto do livro quanto da revista.

Autorizo a divulgação deste depoimento Lorena Lima

As amostras das atividades apresentadas acima, aliadas aos depoimentos dos bolsistas revelam uma harmonia didática importante estabelecida entre os sujeitos envolvidos, durante a realização do projeto. $\mathrm{O}$ ambiente de ensino e aprendizagem instalado favoreceu o protagonismo dos alunos, a partir do momento em que as suas vivências/experiências e anseios interagiram com os textos lidos, transcendendo para a escrita. Por meio da imaginação instigada nas aulas, os alunos-escritores ressignificaram as suas realidades e a manifestaram artisticamente de forma tão singular. Não podemos deixar de sublinhar que as produções dos alunos é que deram voz aos depoimentos dos docentes em formação. Além disso, elas sedimentaram a vontade deles continuarem se (trans)formando. Como reflete (NÒVOA, 1995, p. 24)

O processo de formação está dependente de percursos educativos, mas não se deixa controlar pela pedagogia. O processo de formação alimenta-se de modelos educativos, mas asfixias quando se torna demasiado "educado". A formação vai e vem, avança e recua, construindo-se num processo de relação ao saber e ao conhecimento que se encontra no cerne da identidade pessoal. (NÒVOA, 1995, p. 24)

\section{Conclusão}

O trabalho aqui exposto silencia o texto frio da 9394/96 e marginaliza termos como aperfeiçoamento, capacitação e formação. As respostas aqui dadas vociferam que a formação docente, para além de estar alicerçada em conhecimentos técnicos e metodológicos, deve se pautar em aspectos valorativos capazes de transcender o conteudismo que, não raro, conduz tanto o professor quanto o seu aluno a atividades intelectuais irrefletidas. Nesse sentido, a análise das situações de ensino reais e vivenciadas na sala de aula, as problematizações próprias das relações interpessoais, a necessidade de elaboração e criação de novas formas de ensinar diante dos limites impostos por situações complexas são todos aspectos que agregam a prática formativa e oportunizam o desenvolvimento contínuo do 
senso de autoformação, em consonância com a formação do outro. Sob esse aspecto, evocamos uma oportuna reflexão de Cecília Meireles, segundo a qual, ensinar é "acordar a criatura humana dessa espécie de sonambulismo em que tantos se deixam arrastar. Mostrarlhes a vida em profundidade. Sem pretensão filosófica ou de salvação- mas por uma contemplação poética, afetuosa e participante." Essa postura reivindicada pela poetiza deve fundamentalmente integrar a formação do professor, em qualquer que seja o estágio, inicial ou continuado. Isso fará toda a diferença pois é o professor a primeira figura que iniciará a efetivação de profundas transformações.

\title{
TEACHER TRAINING: REPORT OF EXPERIENCES IN THE CONTEXT OF THE PORTUGUESE LANGUAGE SUB-PROJECT - PIBID / UESB
}

\begin{abstract}
This article seeks to reflect being a teacher and its implications, through the triangulation of think-do-think in Portuguese language classes. For this, an experience (action) from the project entitled Grandes Histórias Escritas por Todos Nós, developed at Colégio Estadual Fernando Spínola, during the academic year of 2019. It should be clarified that the referred project is an unfolding of the Subproject of the Portuguese Language Class/ Middle School of the Institutional Program for Teaching Initiation Scholarships - PIBID/2018. The following subjects were the protagonists in the elaboration and development of this experience (action): the coordinators of the referred subproject; the supervising teacher of elementary school at Colégio Estadual Fernando Spínola; 07 graduates of Vernacular Letters Course at UESB, Campus Vitória da Conquista, the former scholarship holders of initiation to the Teaching of PIBID and, also, students of the 7th and 9th years of Middle School of the referred school in Vitória da Conquista. As a result of this process of teacher/ student (trans) formation, there was the publication of the Pequenos Grandes Escritores magazine, which reveals that teacher training, in addition to being encouraged by public policies, must be experienced not only by the axes of academic preparation; professional preparation and professional practice, but equally, through training that does not dispense with the experiences and personal involvement of all involved.
\end{abstract}

KEYWORDS: Experiences; Teacher training; PIBID.

\section{REFERÊNCIAS}

BRASIL. Lei Federal n 9.394, de 20/12/96 - Estabelece as diretrizes e bases da educação nacional. Disponível em: http://www.planalto.gov.br/ccivil_03/leis/19394.htm Acesso em: 25 de abril de 2020 .

CUNHA, Maria Isabel da. O tema da formação de professores: trajetórias e tendências do campo na pesquisa e na ação. Disponível em: https://www.scelo.br/pdf/ep/v39n3/ aop1096.pdf. Acesso em: 28 de abril de 2020. 
EMEDIATO, WANDER. Aspectos lógicos, críticos e linguísticos do ensino da leitura e da escrita. In: CAMPOS, Lucas; MEIRA, Vivian ( Orgs.) Teorias linguísticas e aulas de português. Salvador: EDUNEB, 2016.

FREIRE, Paulo. Pedagogia do oprimido. 67. Ed. Rio de Janeiro/São Paulo: Paz e Terra, 2019.

MEIRELES, C. disponível em: https://www.pensador.com/frase/MTkzNDU1Mw/.

Acesso em 30 abr. 2020.

MODL, Fernanda; BIAVATI, Nádia Fernandes Dolores; SOUZA, Ester Maria de Figueiredo. A noção de Gênero E9M) Gestos de Transposição Didática: a análise do discurso crítica e a teoria dialógica da linguagem. In: CAMPOS, Lucas; MEIRA, Vivian (Orgs.) Teorias linguísticas e aulas de português. Salvador: EDUNEB, 2016.

NÒVOA, A. Formação de professores e profissão docente. In: formação. 2. ed. Lisboa: Dom Quixote, 1995. p. 13-33. . Os professores e sua

Recebido em: 30/04/2020.

Aprovado em: 27/05/2020. 